\title{
The Evolution of Smart and Intelligent Mobility - A Semantic and Conceptual Analysis
}

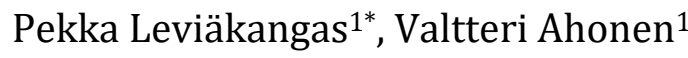 \\ ${ }^{1}$ Department of Infrastructure and Transport, University of Oulu, PO Box 4500, FI-90014 Oulu, Finland
}

\begin{abstract}
Smart or intelligent mobility has been the founding concept to address new technologies needed to develop future transport systems. The development of intelligent mobility has traditionally been much driven by the automotive industry. Research in this domain has traditionally focused on providing safe, comfortable, and affordable mobility to drivers and passengers. As the awareness of the effects of emissions released to the environment by transportation has been increasingly acknowledged, transport systems have since then expected to be "intelligent" also in terms of sustainability. Furthermore, social issues, such as transport poverty and social exclusion, have emerged as key topics. By performing a bibliometric analysis of scientific literature, reviewing inter-governmental policy documents, and analyzing national (Finland) government programs, this paper shows how there has been a shift of thought at conceptual and semantic levels regarding what we perceive as smart mobility. The findings quite clearly suggest that the policy debate as well as research topics have taken the shift first from traffic safety toward technology orientation, and thereafter further toward a more holistic perception of sustainability. "Inclusiveness" appears to be the latest theme in the transport policy debate at the European Union level, although research on it is still marginal.
\end{abstract}

Keywords: Bibliometrics; Intelligent transport; Mobility; Sustainable transport; Transport policy

\section{Introduction}

\subsection{How "Intelligent Transport" was First "Safe"}

Mobility is changing, and it is changing at a compelling pace owing to our need to decarbonize the mobility system and make it more sustainable. Before we were aware of the need for sustainability, we-i.e., the supplying industries, policymakers, planners, service providers, and citizens - only narrowly focused on the technological possibilities offered by digitalization and automation, especially because of the wide-scale adoption of some general-purpose technologies, such as global satellite positioning, light emitting diode (LED) technologies, and wireless communications. Satellite positioning combined with digitalized maps has enabled navigation services. Wireless communications, especially dedicated short-range communication technologies, have enabled road-tolling systems. Moreover, variable message signs have been developed with the help of LED technologies. Internet technologies combined with wireless communications have made public transport ticketing and trip planning easier. These are just samples from a breathtaking list of modern smart mobility applications. 
The US Department of Transportation published The History of Intelligent Transport Systems (US DOT, 2016), which introduces long-term developments in the US. However, probably the earliest appearances of intelligent transport systems (ITS) can be found in Japan during the 1960s when the Comprehensive Automobile Control System (CACS) was being developed. From the US and Japan, the idea of an ITS spread to Europe. One of the first applications that can be considered as an intelligent transport system is traffic signals. They were first pre-programmed analogically to change lights between green and red, and were later equipped with loop sensors to better adapt the signal controls to the changing patterns of traffic flow.

Much of the ITS was driven by the automotive industry, and this took place for obvious reasons. The automotive industry has been, and still partly is, the driving force of the technological development of the transport system. While this may be seen as a one-sided approach that has led to the dominance of private car use, there is a lot we can thank the automotive industry for. The first and foremost thing is safety. Nothing has contributed to traffic safety more than the development of safety technologies by the automotive industry. Today, these technologies are at the core of ITS. Moreover, ITS has developed into an entire industry segment of its own (Leviäkangas, 2013).

The proof for the aforementioned claim of the automotive industry's crucial role can be found in statistics. Road traffic accidents have, across the vast majority of European countries, systematically declined for the last two decades, as can be seen in Figure 1. Obviously, infrastructure improvements have been made, but human behavior has been largely unchanged, and $90 \%$ of all road accidents occur because of human error (ACEA, 2021). Mostly, vehicle safety technologies eliminate human errors. Overall, the obvious conclusion is that safer vehicles are the primary cause of improved safety, without undermining the importance of infrastructure issues that, especially in developing economies, are probably a far bigger factor contributing to accidents.

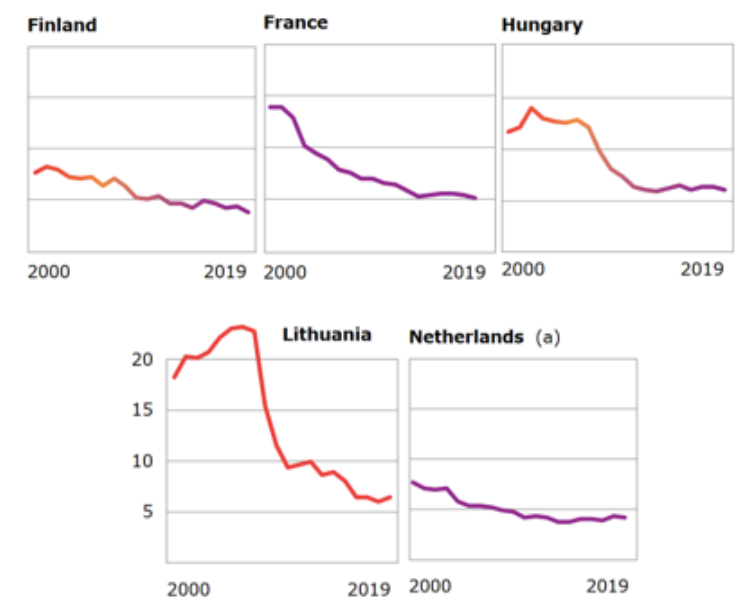

Figure 1 Examples of road traffic safety development in Finland, France, Hungary, Lithuania, and the Netherlands. Note that both Lithuania and Hungary joined the European Union (EU) in 2004, after which there was a period of automobile fleets being renewed due to the opening of the Single European Market (OECD, 2020)

\section{2. "Sustainable" Mobility}

After the Brundtland report "Our Common Future" (United Nations, 1987) was diffused to the minds of decision-makers, it became evident that ITS need to be intelligent not only in terms of technology but also in terms of sustainability. In other words, the questions of pollution, excessive use of natural resources, and, worst of all, the inevitable climate change, which is already showing its first impacts, became evident. The transport system needs to 
change so that pollution and greenhouse gas emissions are radically cut and ultimately stopped.

Today, in Europe, emissions from transport amount to a quarter of the total emissions, as seen in Figure 2. The international shipping and aviation sectors are by far the greatest contributors to greenhouse gas emissions (Figure 3). With these starting points in mind, it is unsurprising that transportation is one of the key sectors to be addressed in terms of sustainability, not least because of the climate challenge.

However, sustainability addresses many aspects, not just climate and greenhouse gas emissions. Other emissions, such as noise and particles, cause severe health problems (see, e.g., Leviäkangas, 2020). In many European cities, old diesel engines have been recently banned because of aerial particulate emissions, which are particularly harmful to human health. These include, for example, Barcelona, Paris, London, Brussels, Stuttgart, and Milan (however new Euro 6 models are allowed throughout most European cities; Diesel Information Hub, 2021). Lastly, emissions to ground and water include microplastics from tires and toxic heavy particles. All these aforementioned aspects related to sustainability directly affect the cost of transport systems and mobility (Leviäkangas and Hautala, 2011), which makes the sustainability issue a hot topic in science and politics.

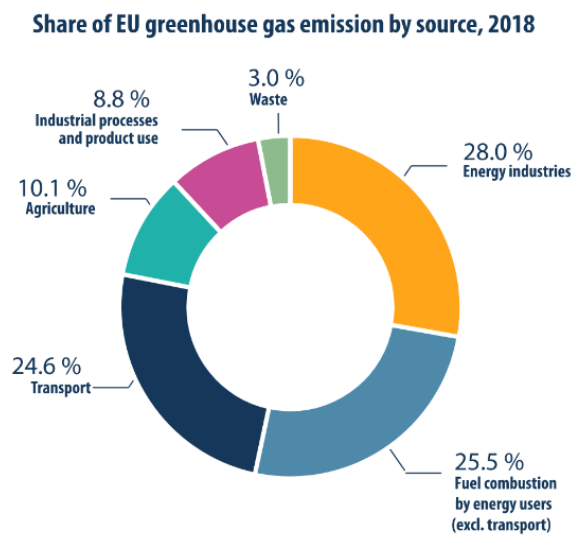

Figure 2 Greenhouse gas emissions by sector in the EU in 2018 (Eurostat, 2021)

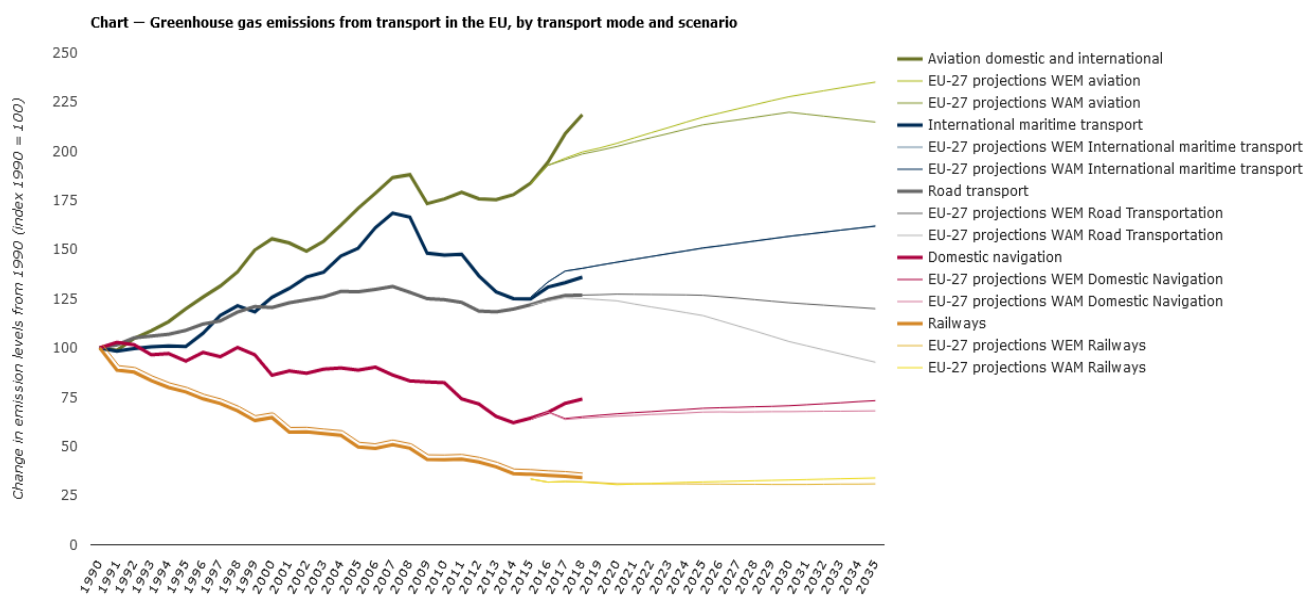

Figure 3 Greenhouse gas emissions, historical and scenarios, from the transportation sector in EU27 with existing measures (WEM) and with additional measures (WAM; European Environment Agency, 2021)

\section{3. "Inclusive" Mobility}

The latest attribute of the Smart City concept is probably "inclusiveness." What does it mean? The World Bank addresses inclusiveness from two directions, which are also part of 
the bank's mission. The first motive is reaping the benefits from urbanization. Urban centers are concentrating the population such that by $2050,70 \%$ of the global population is estimated to live in cities, either larger, middle-sized, or smaller. In addition, $80 \%$ of the world's gross domestic product (GDP) is generated in cities. This means that people in cities are entitled to enjoy the benefits of economic growth, whereas we have seen, especially in mega-cities, that urbanization has brought forth a number of problems, such as social exclusion due to loneliness, lack of social networks, and poverty due to high accommodation prices and living costs (World Bank, 2021). Thus, the second motive springing from Sustainable Development Goal 11 calls for "inclusive, safe, resilient and sustainable cities."

In Europe, inclusiveness also contains social rights and citizens' engagement aspects. Inclusive cities are seen as those where power-sharing is between city officials, city developers, and the citizens. For example, the city of Turku, the second largest city in Finland, pledges for equal opportunities for all and active support for employment (Eurocities, 2021). The inclusiveness attribute seems to manifest the most recent step as a change in the thinking of the policymakers, from technology orientation to human and social orientation.

\section{Purpose, Scope, and Analysis Data}

The purpose of this paper is to show, via a bibliometric analysis, how there has been a shift of thought regarding what we perceive as "smart mobility." The evolution is clearly visible when analyzing the keywords and titles of scientific literature and reviewing government, ministry, and agency documentation, such as their strategies, vision statements, and long-term objectives. The a priori assumption of a changing thinking as well as rhetoric is tested using three methods of observation:

- First, a bibliometric analysis is conducted to witness the change in the keywords and titles of peer-reviewed scientific publications. Web of Science is used for searching scientific articles with different sets of keywords from the chosen period. Search results are reviewed, and changes in annual scientific production and the most relevant keywords are observed.

- Second, the recorded policy documentation of the European Economic and Social Committee (EESC) is analyzed to detect how the concept of "smart mobility" has evolved over time. This is done by observing the number of documents containing the terms defined in the public documents from the committee. The committee comprises employers, trade unionists, and representatives of social, occupational, economic, and cultural organizations. It is appointed for a renewable 5-year term by the European Council on a proposal by the member states.

- Third, as the most detailed level of observation, the programs of the Government of Finland are reviewed to see how the rhetoric has changed when expressing the preferred future state-of-the-world in terms of smart and sustainable mobility. The terms are the same as those in EESC document analysis.

The period for the bibliometric analysis of the scientific literature in Web of Science and European Committee policy documentation is 1995-2020. This is because the terms searched started appearing during that time. Data on scientific article keywords were not available for 1995; therefore, the data starts from the year 2000. Finnish government programs were reviewed from 2007 because the analysis in scientific literature and EC policy documentation suggest the first shift in development trends around that time. 
Finally, a discussion, based on the researchers' experience and heuristics, is presented, where the next conceptual shifts or directions regarding ITS are predicted.

\section{Bibliometric Analysis}

\subsection{Web of Science Search Analysis}

Web of Science article searches were analyzed by observing the annual change in the scientific production of articles with different keywords related to transport and mobility research. In addition, the peak appearances of the keywords were extracted by dividing annually written articles with the maximum annual production of articles within that period. In Figures 4 and 5, changes in the focuses of the research can be seen. "Intelligent transport" and terms related to it seem to dominate the papers written in the field; however, in the 90's, "traffic safety" appeared in articles more times compared with "intelligent transport".

In Figure 5, the most relevant keywords (top 30) of the articles written in 2000, 2005, 2010, 2015, and 2020 have been examined and categorized in themes by the second author. Because the annual production of articles is changing, keyword appearances are compared with the total number of the 30 most relevant keyword appearances in the articles. This analysis shows that keywords related to traffic safety are declining, while security has become more relevant. In addition, sustainability has reached a stable position in the list of the most relevant keywords. Enabling technologies, such as the Internet of Things, Big Data, feature extraction, and autonomous vehicles, are emerging in the list of most relevant keywords more frequently. Smart city has also appeared in the keyword list.

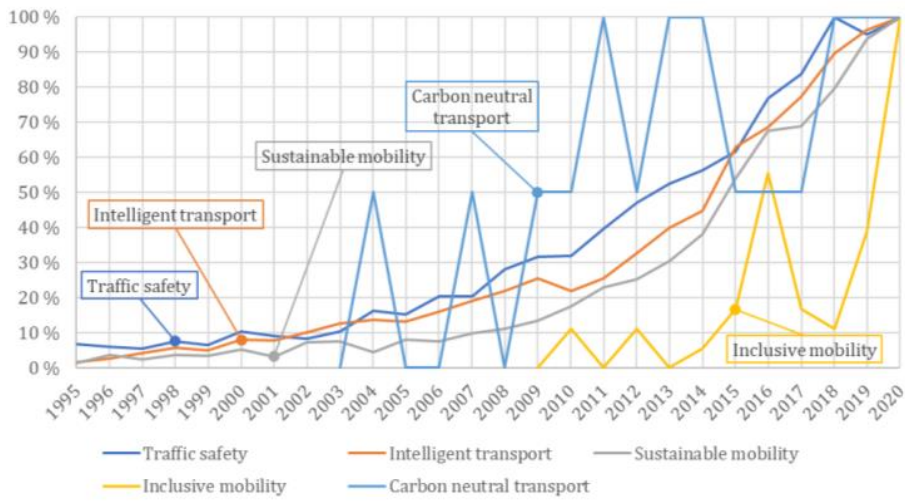

Figure 4 Comparison of peak time appearances of the articles related to traffic safety, intelligent transport/mobility, sustainable transport/mobility, inclusive transport/mobility, and carbon neutral transport/mobility

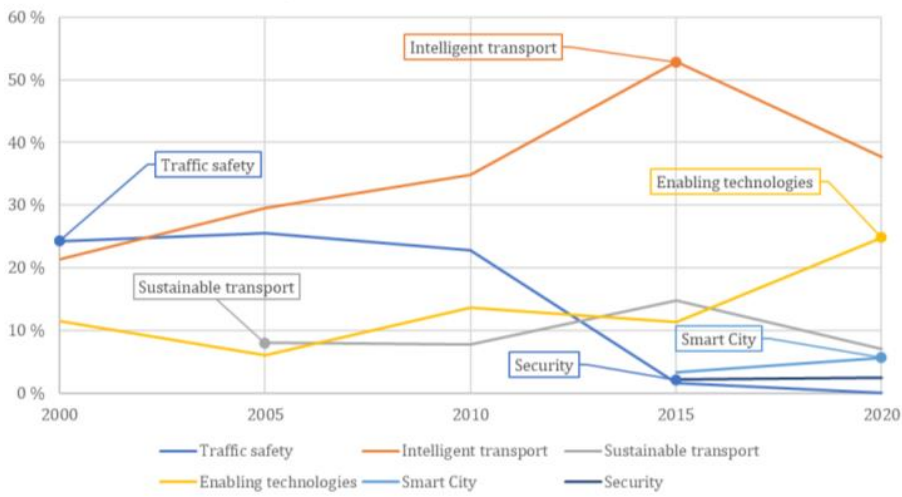

Figure 5 Change in themes over time in the 30 most relevant keywords in the field of transport and mobility 
There seems to be an inconsistency between the annual scientific production of articles and the appearance of the keyword traffic safety. Figure 4 suggests that the number of scientific articles related to traffic safety continues to increase, which is well in line with the bibliometric analysis done by Zou et al. (2020). However, in Figure 5, it seems that the traffic safety aspect does not appear in the top keywords anymore. One explanation for this might be that scientific literature related to intelligent transport systems concentrates on the technology used in the development of transport systems, which then further enhances traffic safety.

The bibliometric analysis conducted by Gamboa-Rosales et al. (2020) supports this explanation by categorizing sub-themes in ITS research into advanced public transportation systems, autonomous vehicles, connected vehicles, geospatial information systems, highway road management, intelligent vehicles, network mobility, smart cities, traffic management, traffic simulation, vehicular ad-hoc networks, and vehicular communication. Basically, this means that themes in ITS relate heavily to the technology enabling ITS; therefore, the sustainability aspect is also decreasing in the most used keywords with traffic safety. Nevertheless, sustainability is considered to be derived from digital technologies and innovations, as stated by Berawi et al. (2020) and Berawi (2020).

\subsection{EC Policy Documents Analysis}

The EC documents were analyzed by reviewing the European Economic and Social Committee's public opinion documents. The analysis somewhat shows how the rhetoric has moved over the last two decades or so. Figure 6 demonstrates the shift and provides rough indirect evidence of how policy focus has changed in terms of rhetoric: "Safety" was at its peak approximately 10-15 years ago, followed by "intelligent transport" a few years later (peak in 2009 and a steady decline afterward). For "sustainable" and "inclusive mobility," the peak year coincided with 2012, to be clearly overtaken in 2020 by "carbon neutrality." Figure 7 shows that similar to the term "intelligent mobility," the appearance of the term "smart mobility" has had its peak and is slowly declining.

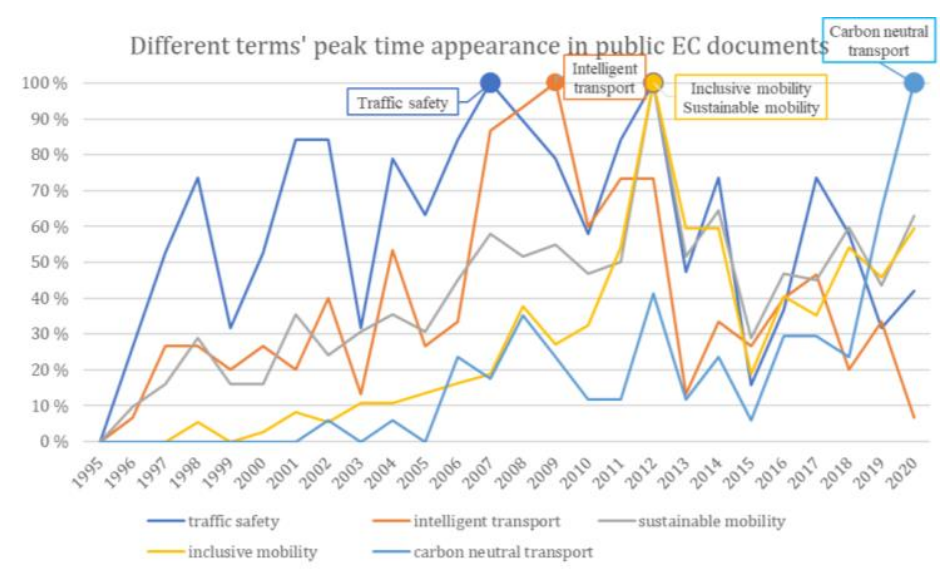

Figure 6 Appearance of "Traffic safety," "Intelligent transport," "Sustainable mobility," "Inclusive mobility," and "Carbon neutral transport" as a percentage of the peak frequency (100\% is the peak). "Safety" precedes "intelligence," followed by "inclusive" and "sustainable," and then ending with "carbon neutral"

It seems that the European policy debate at the level of European policymaking has taken the shift from traffic safety first toward technology orientation ("intelligent transport") and then further toward a more holistic perception of what we consider sustainable. The most recent rhetoric seems to be focusing on climate issues in terms of cutting greenhouse gas emissions from transport. This is understandable as the costs to 
climate change adaptation and mitigation of climate warming start to become evident, and it is expected that the debate will get more heated in the years to come.

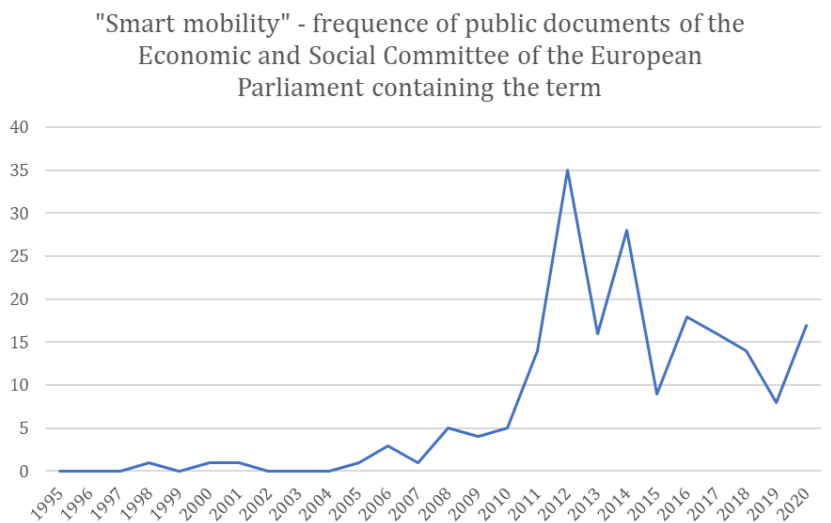

Figure 7 How "Smart Mobility" was present in the discussions and opinion papers published by the European Economic and Social Committee. The peak year is 2012, after which a steady decline is observable

\subsection{The Government Programs of Finland}

The government programs reflect policy orientation through their use of words and terms. A similar analysis was conducted for the following government programs, arranged in ascending chronological order (The Finnish Government, 2021):

- Programme of Prime Minister Sanna Marin's Government, December, 10, 2019, "Inclusive and competent Finland- a socially, economically and ecologically sustainable society"

- Programme of Prime Minister Antti Rinne's Government, June, 6, 2019, "Inclusive and competent Finland- a socially, economically and ecologically sustainable society" (note the title is the same as the one mentioned above)

- Programme of Prime Minister Juha Sipilä's Government, May, 29, 2015, “Finland, a land of solutions"

- Programme of Prime Minister Alexander Stubb’s Government, June, 24, 2014, "A new boost for Finland: growth and employment"

- Programme of Prime Minister Jyrki Katainen's Government, June, 22, 2011, “An open, fair and confident Finland"

- Programme of Prime Minister Mari Kiviniemi's Government, June, 22, 2010, "Finland towards a consistent path to growth, employment and stability"

- Programme of Prime Minister Matti Vanhanen's second Government, April, 19 2007, “A responsible, caring and rewarding Finland"

The following words or terms were sought, and their number of appearances with respect to transport or mobility were counted: "safety," "intelligent," "sustainable," "inclusive," and "carbon". The idea was to have a corresponding mapping of the policy foci and rhetoric of each government in power. The results of this simplistic bibliometric analysis, which are illustrated in Figure 8, show that traffic safety has kept its position as one key national transport policy issue, whereas the technology-oriented term intelligent transport or mobility had its peak around the early 2010s, during Mr. Katainen's government. This observation is well in line with the observations from the EC's Economic and Social Committee's work. Equally, "sustainability" is increasing its weight in the political debate. It is noteworthy that some short-lived governments do not even mention 
the sought terms, showing perhaps some negligence toward the relevant issues that should have been addressed.

An interesting observation is that inclusiveness is not addressed by any of the listed government programs. It will be interesting to witness whether this shift in rhetoric will take place the same way as it did in the debate at the European level or whether it will remain unattended by Finnish national politics.

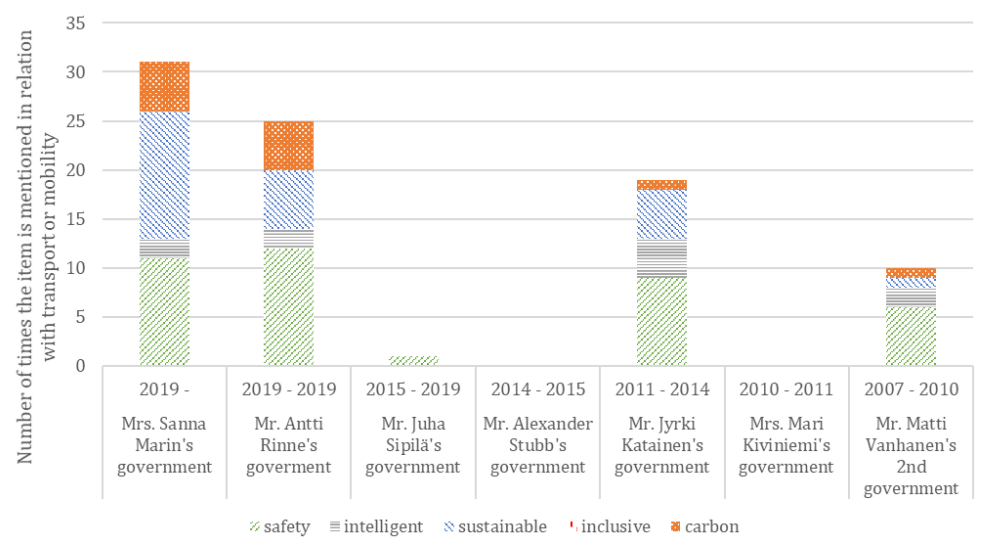

Figure 8 How relevant terms are present in government programs of Finland in connection with transport and mobility. The role of sustainability and low-carbon issues has increased over time

\section{What Are the Next "Viralities?"}

After seeing that smart mobility is a "living thing," not only in terms of terminology but also how we perceive it through our use of words and meanings, it is worthwhile to think about where smart mobility is going and what we should expect in the future. This may be an impossible question to answer precisely, but there might be a few justified predictions that can be made. These predictions are those of the authors only and are made on a heuristic basis.

First, as transport systems are becoming technologically more complex, there will be issues concerning who is able to maintain and manage these systems. Present ITS is a universally connected system of systems. Payment systems, control systems, scheduling systems, fleet management systems, traffic management systems, and infrastructures supporting all these systems are already more or less interconnected. The questions of ownership and stewardship are gaining increasing attention. As larger and increasingly complex systems are procured and implemented, buyers - who are in many cases public authorities-have neither the expertise nor capacity to maintain and effectively operate such systems. Hence, procurement must be based on build-operate procurement models, and even more often on design-build-finance-operate principles. This will give more power to suppliers in the long run and may tie procurers into multiple types of lock-ins. The abovedescribed features can be regarded as aspects of manageability.

Second, the pursued functionalities and impacts are gaining increasing attention instead of technological sophistication. The technologically most advanced alternatives may not be more cost-effective compared with less advanced but manageable and more controllable options. A great deal depends on the negotiation power of the two sides, i.e., supplier and procurer. Much also depends on the trust and confidence that the two sides have toward each other, and one cannot underestimate the importance of clarity of objectives of the procurer and how these objectives are translated into performance criteria for the procured system. In short, system procurement and implementation will become much more performance-based and built on trust and reputation. These aspects can be 
called credibility, underlining the need to have systems that perform as expected and "get the job done."

Third, sustainability issues will remain the focus, but sustainability will have more dimensions than it has now. Sustainability is generally divided into environmental, social, and economic sustainability, of which the environmental aspect has been the most popular topic in the relevant literature (Puig et al., 2021). The recent emergence of "inclusiveness" shows that the importance of social sustainability has been realized. Furthermore, the sustainability aspect can be extended to take into account life-cycle considerations, maintainability, ethical considerations, and security and safety, including cybersecurity, which will play a role in the making of smart and sustainable mobility in the future. It is difficult to find the right word for this attribute, but perhaps it is best described as stability or steadfastness. In addition, resilience could be considered a descriptive attribute.

Fourth, urban aspects are gaining more attention. The simple fact is that urbanization is still progressing around the world. This will make urban mobility issues even more burning than what they are today. The social aspects that follow urbanization will also be reflected in urban mobility. Transport poverty, social fairness, and the resilience and reliability of the system will be on the agenda with great certainty. Their relative role largely depends on the overall development of the society-an unstable society will not be able to foster a reliable and resilient mobility system; moreover, it cannot support urban inhabitants to make full use of their capacities. The mobility system is, in the end, just a reflection of the societal system surrounding it and a tool to deliver opportunities, wellbeing, and quality of life. The word that could describe these needs is empowering, creating equal opportunities and enabling people to improve and advance their lives.

Fifth, digital platforms will be playing a crucial role in the future. The platforms take different shapes and operating logic, but the commonality is that they integrate different services to be accessed via a single portal. Grab is probably one of the best and most successful examples. In addition, Amazon, Google, Alibaba, Facebook, etc., can be understood as digital platforms allowing B2C, B2B, and even B2G and G2C transactions and information exchange to take place. Sometimes the market power of these platforms can be considered so dominant that it will raise public concerns (as some have done in the EU). What platforms are clearly able to do is that they create scalability, even to the extent where they scale up to a monopolistic position.

Finally, at the end-user market level, consumers and end-customers are becoming increasingly conscious of the aforementioned dimensions and implications of the services they consume; consequently, their behavior may be affected. For example, if electric vehicles prove to be fire-risky or difficult to recycle, or if the raw materials needed for them have unethical consequences, the entire demand logic for such services and products may collapse very quickly, even if other earlier consumer issues (Zulkarnain et al., 2012) have been solved. This implies that the market projections and expectations regarding whichever smart mobility aspect we are thinking of will be highly uncertain. This, in turn, will have implications for investor behavior, public investments, and risk premia adopted by business ecosystem actors. This is the prediction of having ethics at the core of future smart mobility.

\section{Conclusions}

For smart or intelligent transport, both research and policymaking are changing. Moreover, the foci of research and policymaking have changed from safety to technology orientation and then to sustainability orientation. The shifts are observable in scientific 
literature, European policy documents, and national policymaking. The shifts can be timed and summarized as follows:

- The first shift: traffic safety is surpassed by intelligent transport/mobility around 2005-2010, when intelligent transport systems made their first grand entry, largely driven by the automotive industry and enabled by different market-ready technologies.

- The second shift was from intelligent transport/mobility to sustainable transport/mobility as climate change became strongly present in sectoral policy agendas; this took place right after the first shift around 2010.

- The third shift occurred when sustainability came to include more dimensions than just climate change and emission of greenhouse gases; the shift started around 2015 and is probably still ongoing. The United Nations Sustainable Development Goals had much to do with this shift.

- New dimensions of sustainability can be expected to emerge from politics, research, and general societal debate. For example, questions of manageability, ethics, and credibility are predicted to be among the key future attributes for smart mobility systems.

What is quite interesting and noteworthy is the fact that research (or to be more precise, transport research) did not direct the above-described changes. We are educated to think that research is directing new waves of thinking and public debate, including policymaking, but that does not seem to be a straightforward case. This observation is definitely worth some further analysis and consideration, especially for researchers.

\section{Author Contributions}

Prof. Leviäkangas authored most of the paper and performed the analysis on policy documentation. Mr. Ahonen wrote sections of the text, performed the scientific literature analysis, and finalized the manuscript.

\section{Acknowledgements}

The anonymous reviewers of The $2^{\text {nd }}$ CSID AUN-SCUD International Conference on Sustainable Infrastructure and Urban Development are gratefully acknowledged for their efforts toward improving this paper. This research has been supported by the European Union H2020 program (AURORAL project, Grant agreement ID: 101016854) (AURORAL, 2021).

\section{References}

ACEA, 2021. Road Safety Facts. Available Online at: https://www.roadsafetyfacts.eu/aboutus/, Accessed on September 29, 2021

AURORAL, 2021. AURORAL. Available Online at: https://www.auroral.eu/\#/p-about, Accessed on September 29, 2021

Berawi, M.A., 2020. Managing Nature 5.0: The Role of Digital Technologies in the Circular Economy. International Journal of Technology, Volume 11(4), pp. 652-655

Berawi, M.A., Suwartha, N., Asvial, M., Harwahyu, R., Suryanegara, M., Setiawan, E.A., Surjandari, I., Zagloel, T.Y.M., Maknun I.J., 2020. Digital Innovation: Creating Competitive Advantages. International Journal of Technology, Volume 11(6), pp. 10761080

Diesel Information Hub, 2021. Where in Europe can I Drive My Diesel Car? Available Online at: https://dieselinformation.aecc.eu/where-in-europe-can-i-drive-my-diesel-car/, Accessed on September 29, 2021 
Eurocities, 2021. Eurocities. Available Online at: https://eurocities.eu/, Accessed on September 29, 2021

European Environment Agency, 2021. Evolution of GHG Emissions from Transport in the EU-28. Available Online at: https://www.eea.europa.eu/data-andmaps/daviz/evolution-of-ghg-emissions-in-2\#tab-chart_1, Accessed on September 29, 2021

Eurostat, 2021. How are Emissions of Greenhouse Gases by the EU Evolving? Available Online at: https://ec.europa.eu/eurostat/cache/infographs/energy/bloc4a.html?lang=en, Accessed on September 29, 2021

The Finnish Government, 2021. Government Programmes since 1917. Available Online at: https://valtioneuvosto.fi/en/government/history/government-programmes-since1917-new, Accessed on September 29, 2021

Gamboa-Rosales, N.K., Celaya-Padilla, J.M., Hernandez-Gutierrez, A.L., Moreno-Baez, A., Galván-Tejada, C.E., Galván-Tejada, J.I., González-Fernández, E., Gamboa-Rosales, H., López-Robles, J., 2020. Visualizing the Intellectual Structure and Evolution of Intelligent Transportation Systems: A Systematic Analysis of Research Themes and Trends. Sustainability, Volume 12(21), pp. 1-30

Leviäkangas, P., Hautala, R., 2011. Eco-Pricing of Mobility. International Journal of Technology, Volume 2(2), pp. 102-111

Leviäkangas, P., 2013. Intelligent Transport Systems-Technological, Economic, System Performance and Market Views. International Journal of Technology, Volume 4(3), pp. 288-298

Leviäkangas, P., 2020. Addressing Sustainability or Following Political Climate Rhetoric? Anatomy of Government Agency's Performance Management. Case Studies on Transport Policy, Volume 9(1), pp. 191-199

Puig, N.B., Casado, E.S., Mauleón, E., 2021. Analysis of Social, Environmental and Economic Sustainability Core: A Bibliometric Overview. International Journal of Innovation and Sustainable Development, Volume 15(4), pp. 356-380

OECD International Transport Forum, 2020. Available Online at: https://www.itfoecd.org/road-safety-annual-report-2020, Accessed on September 29, 2021

United Nations, 1987. "Our Common Future". Report of the World Commission on Environment and Development, USA

US DOT, 2016. The History of Intelligent Transportation Systems. Available Online at: https://www.its.dot.gov/history/pdf/HistoryofITS_book.pdf, Accessed on September 29, 2021

The World Bank, 2021. Inclusive Cities. Available Online at: https://www.worldbank.org/en/topic/inclusive-cities, Accessed on September 29, 2021

Zou, X., Vu, H.L., Huang, H., 2020. Fifty Years of Accident Analysis \& Prevention: A Bibliometric and Scientometric Overview. Accident Analysis and Prevention, Volume 144, https://doi.org/10.1016/j.aap.2020.105568

Zulkarnain, Leviäkangas, P., Tarkiainen M., Kivento, T., 2012. Electric Vehicles Market Outlook - Potential Consumers, Information Services and Sites Test. International Journal of Technology, Volume 3(2), pp. 156-168 